\title{
The evaluation of road safety performances in urban areas
}

\author{
S. Raicu, D. Costescu \& S. Burciu \\ University Politehnica of Bucharest, Romania
}

\begin{abstract}
The state of road accidents in Romania, especially in urban areas, underlines the need for research on identifying the appropriate measures for road safety enhancement. In this paper we present the results of research on road safety, specific to urban areas and to Bucharest City. The first part of the paper describes the structure of the model developed for evaluation of road safety performances in urban areas for different traffic intensity patterns. The initial level of modelling includes procedures for the representation of the macroscopic urban road network, starting from the representation of the digital urban area, with junctions and street sections classified according to their capacity and functionality. The second level of the model contains functions for estimating the safety performance of the urban transport network. Each category of elements with low safety performance is analysed, taking into account the physical network characteristics, the traffic flow intensity and accidents statistics. The second part of the paper presents the definition and calibration of the safety performance function for sections of the urban road network from Bucharest. The set of defined safety performance functions will be a useful tool for identifying the possible solutions and measures for safety enhancement.
\end{abstract}

Keywords: urban road safety, safety performance function, urban transport network modelling.

\section{Introduction}

Road safety represents a main societal issue and constitutes a constant objective of policies and regulations developed and applied in transports. The statistics of road accidents recorded in Romania, presented in national and European reports, [1], emphasises the need and importance of the research on road safety 
enhancement. Although after 2008 a decreasing trend of road accidents is observed in Romania, the rate of fatalities per million inhabitants remains much higher than in the EU (Figure 1).

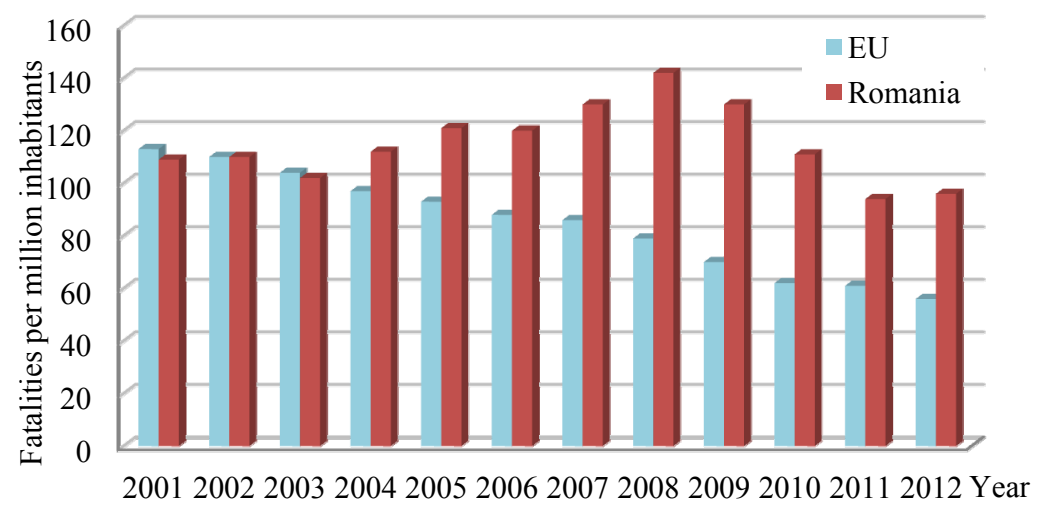

Figure 1: Comparison of road accidents fatalities by population in EU and Romania.

In 2012 the fatalities per million inhabitants registered in Romania were $71 \%$ higher than the EU average.

In Romania an important proportion of the total number of fatalities took place inside urban areas (Figure 2). In 2010, from EU countries Romania had the highest rate of urban road accident fatalities per million inhabitants (it was seven times higher than in Sweden) [1]. In 2012, 61\% of fatalities are recorded in accidents on urban roads. This state underlines the necessity of studies on urban road safety and is one of the main reasons of starting the project "Research on estimation and enhancement of intrinsic safety performances for urban traffic networks". The primary objective of the project is the improvement of the urban road safety by initiating measures for road accident risk diminishing in urban areas identified as zones with low safety performances. This paper presents results of the first phase of the project.

\section{The structure of the model for estimating of the safety performance}

In order to obtain accurate accident estimation it is necessary to develop a complex model, including besides a network model with physical, geometrical and technical characteristics, also a macroscopic digital network appropriate for traffic macrosimulation.

The initial phase of the model (Figure 3) needs the representation of the digital urban road with description of the following features:

- Network geometry, defined by nodes and edges; 
- Classification and codification of edges function on their importance evaluated by road category (avenues, major and arterial streets, collector streets etc.), capacity (number of lanes, lane width), transit lines (section with both road lanes and tram or light-train tracks, dedicated bus lanes etc.), speed and flow intensity, congestion rate;

- Curves speed-traffic flow (which have an essential role in modelling);

- Classification and codification of intersections which are network component with frequent traffic problems.

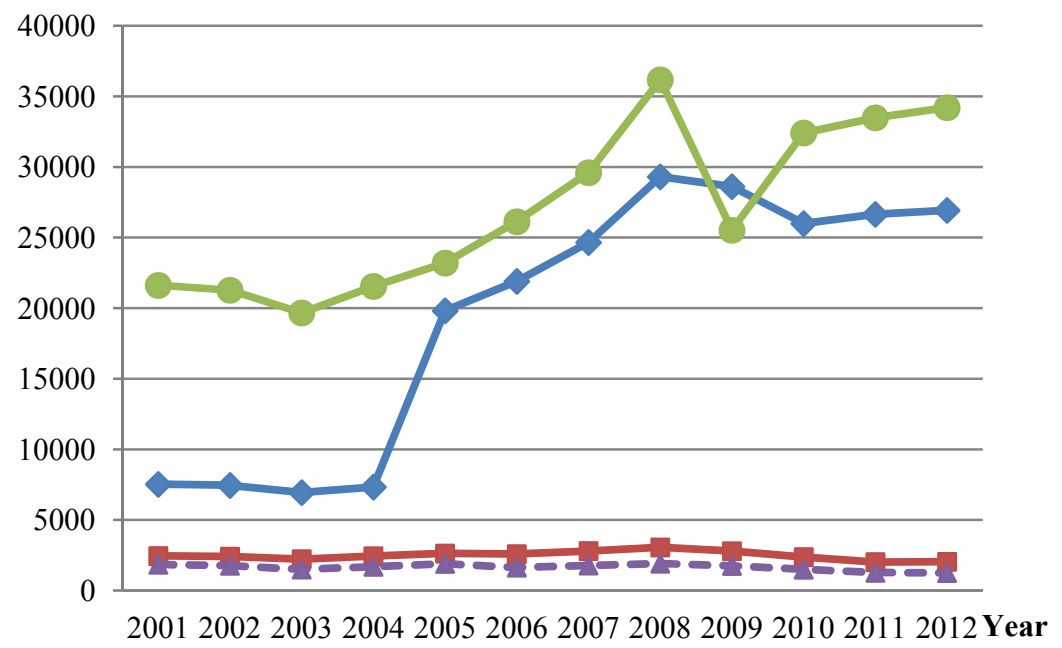

Legend

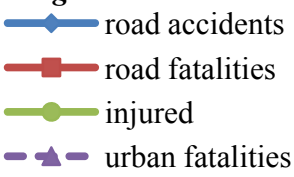

Figure 2: Road safety evolution in Romania.

Starting from the digitized urban physical network the appropriate macroscopic digital network is modelled. The macroscopic digital network is defined by nodes (which may correspond to physical intersection or point where local traffic is assigned), centroid zone connectors and links (which may correspond to section of the major and arterial roads). Each feature of the macroscopic digital network has assigned a code (Figure 4) formed by digits which give information about type and category of road infrastructure, number and width of lanes, signalization, category and configuration of transit lines and stops, configuration of pedestrian crossing, median islands, adjacent street parking system.

The macroscopic digital network has to be base for assigning of the traffic flows. Therefore, the codification and digitization of the urban transport network features are important steps because the result will characterize the topological 
assignment pattern of the traffic flows. The codes of macroscopic digital network allow the selection of the features with same characteristics. For each selected feature class, on the basis of traffic flows intensity, characteristics (given by digits code) and accidents statistics, the appropriate form of safety performance function (SPF) is defined and calibrated.

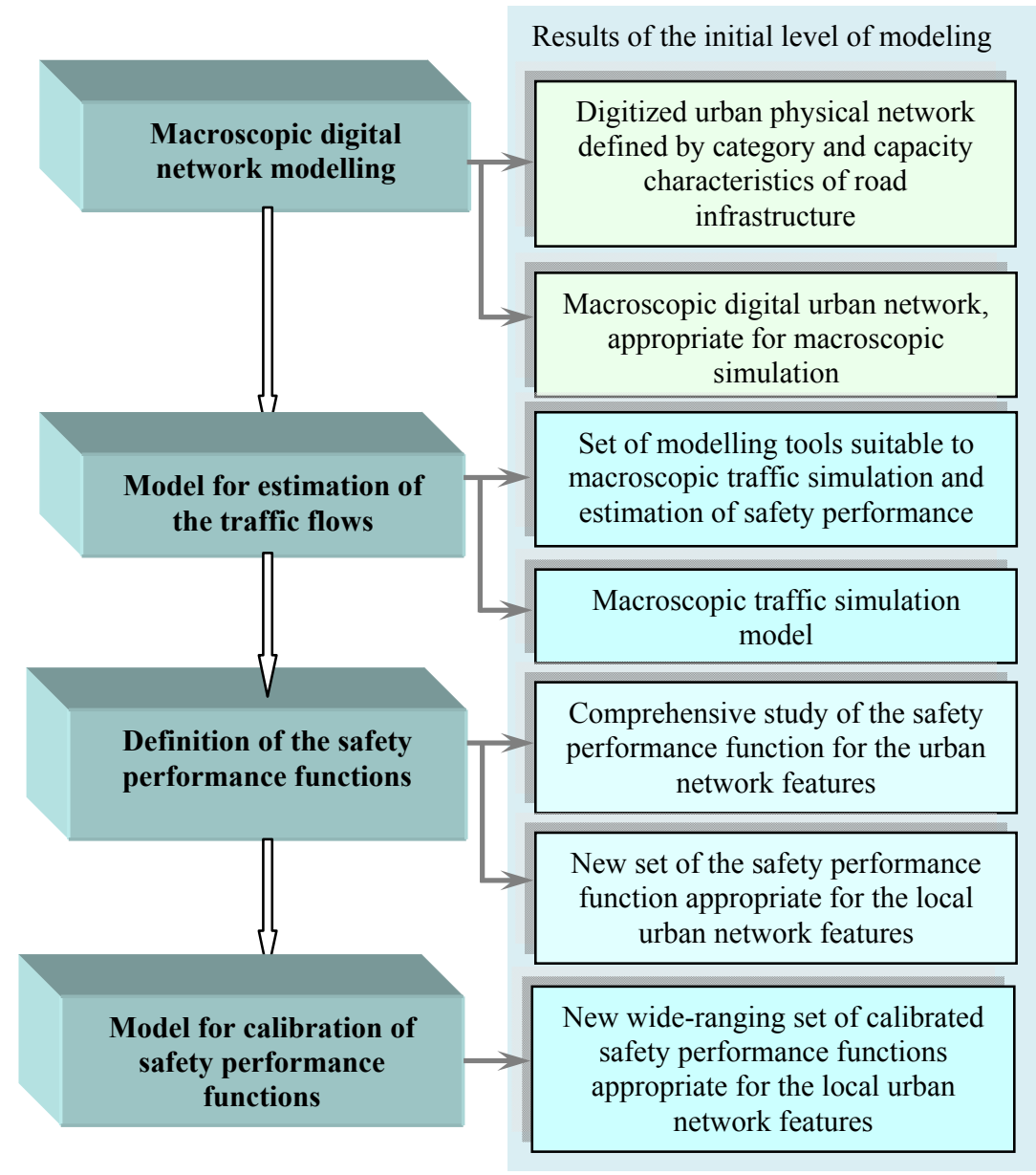

Figure 3: The steps of the initial level of modelling.

The complex model for SPF estimation is developed based on macroscopic digital urban network, geodatabase of the urban physical network and the set of safety performance functions. Figure 5 illustrates the logical sequence of the main phases performed for SPF estimation. Based on the analysis of the network features with low safety performances, the possible solutions to improve the safety performance will be identified. 


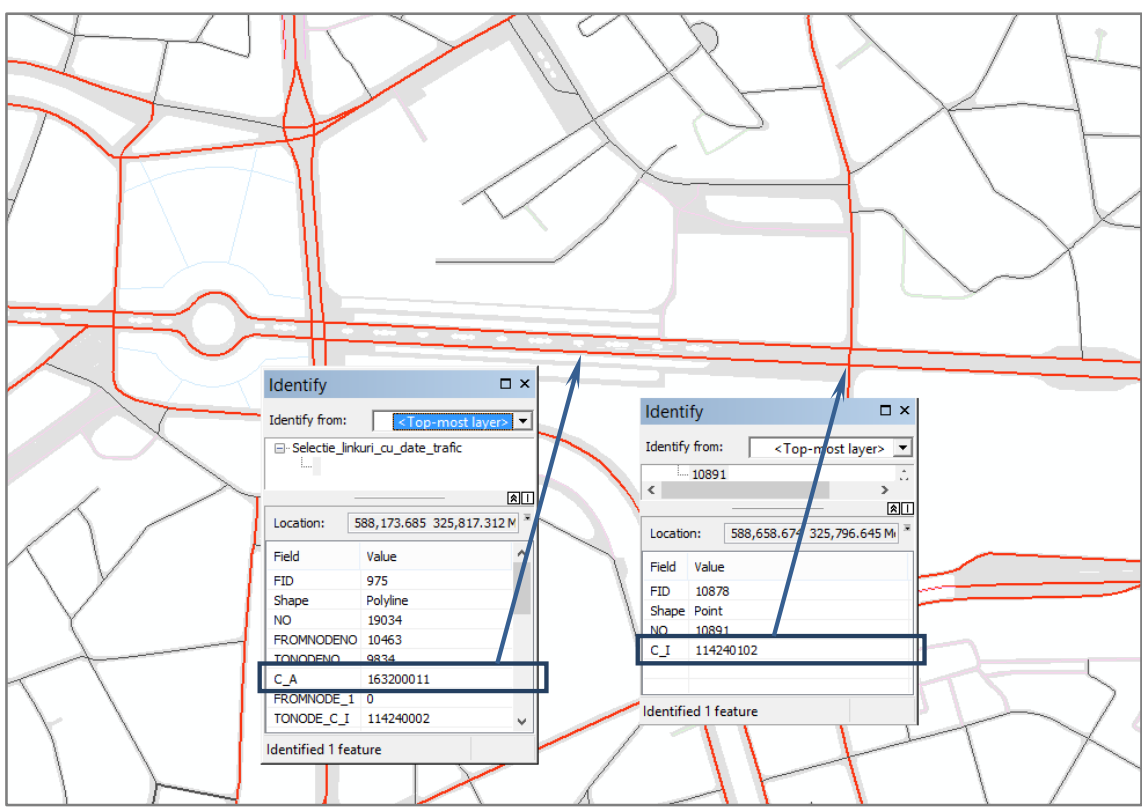

Figure 4: Codification of intersections and edges in the macroscopic digital urban network model.

The next section presents results of the study performed for definition and calibration of safety performance function for sections of urban road network from Bucharest.

\section{Safety performance functions for urban network features}

The concern and the studies in predicting accidents in transportation networks lead to definition of the several categories of SPFs for motorways [2, 3], for rural areas crossed by motorways [4] and for the urban network [5-7].

For urban road networks three main categories of functions could be defined:

- Functions applied on the section between intersections (mid-block);

- Functions developed for estimating the accidents number in major intersections, where flows from major and arterial streets interact;

- Functions for estimating the accidents number in minor intersections, where flows from major and arterial streets and flows from collector and residential streets interact.

Defining and calibration of the correct SPF for each urban road feature category is a complex issue. The SPF parameters can differ significantly function on configuration of intersection and section, type of vehicles, functionality of urban area etc. Therefore SPFs have to be defined and calibrated for different classes of network features, different traffic conditions. The choice of risk variables is performed based on analysis of traffic flows and detailed statistics of road accidents. Thus this selection depends in large measure on data availability. 


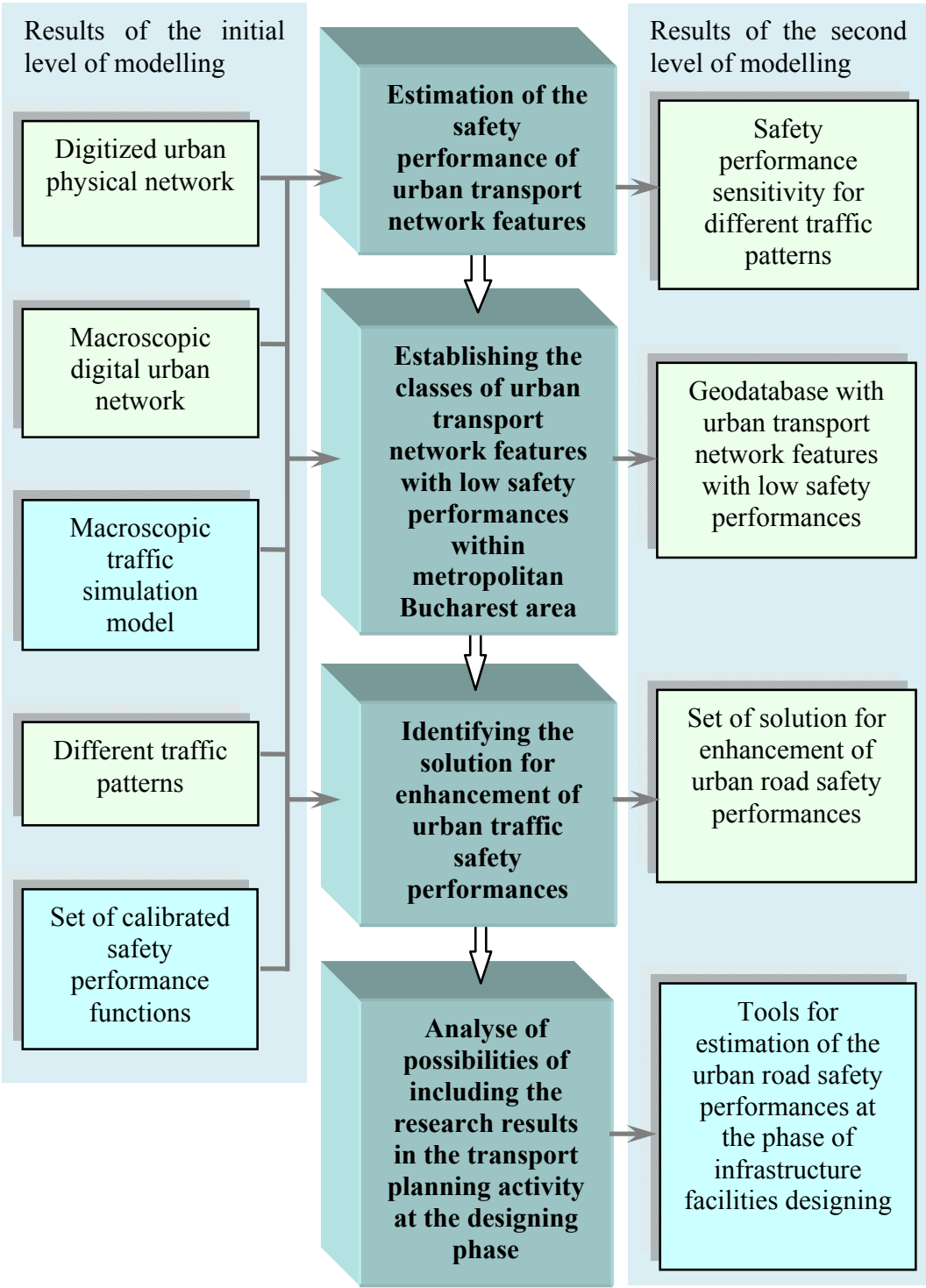

Figure 5: The structure of the model for estimating of the safety performance of urban transport network.

Generally, the variables and parameters included in SPF hang on:

- Existence of the previous studies about variables and parameters with influence on road safety; although at European level there are several studies for definition and calibration of SPF, until now there are no 
quantification for the features and peculiarities of road network from Romania and especially no specific study for Bucharest metropolitan area.

- The capacity of quantification and calibration on the basis of measurements which can be performed and identified as relevant.

Taking into account the large size of Bucharest road network and its high rank of inhomogeneity, even at macroscopic level, and the lack of an historic of traffic flows measurements, for the present study we choose to define the "risk of accidents frequency" as accidents/(vehicle-km) for the road section with available traffic data.

In order to estimate the SPFs parameters, statistical reports on roads accidents from Bucharest were processed and analysed. The data about road accidents recorded in period of 2008-2012 were classified by causes (Figure 6) and were used to add supplementary attributes about accident characteristics in the macroscopic urban network model and to identify the peculiarities of urban areas marked as high risk zones (Figure 7). The supplementary attributes are useful for calibration of SPFs parameters.

For this paper, we choose to exemplify the SFP calibration for the selection of road sections shown in Table 1, for which we obtain the following SPF:

$$
A=\alpha \cdot e^{\beta \cdot x_{1}+\delta \cdot x_{2}},
$$

where $A$ represents the number of accidents in the period of accidents registration (5 years) per length of section (in $\mathrm{km}$ );

$\mathrm{x}_{1}-$ number of lanes on the section (Table 1);

$\mathrm{x}_{2}$ - type of adjacent street parking (Table 1);

$\alpha, \beta, \delta$ - parameters to be estimated.

From eqn. (1) results:

$$
\ln A=\ln \alpha+\beta \cdot x_{1}+\delta \cdot x_{2} .
$$

Using the data of the features with ID 7, 9 and 11, tab. 1, and eqn. (2), the next system of linear equations is obtained:

$$
\left\{\begin{array}{l}
2.20=\ln \alpha+6 \cdot \beta \\
2.56=\ln \alpha+6 \cdot \beta+\delta \\
2.40=\ln \alpha+8 \cdot \beta+2 \cdot \delta
\end{array}\right.
$$

with the solutions: $\delta=0.36, \beta=-0.26, \ln \alpha=3.76$.

Under these conditions, for the analysed period results:

$$
A=43.9 \cdot e^{-0.26 \cdot x_{1}+0.36 \cdot x_{2}} \text { accidents } /(5 \text { years }-\mathrm{km}),
$$

or the average accidents per unit length:

$$
A_{1}=8.78 \cdot e^{-0.26 \cdot x_{1}+0.36 \cdot x_{2}} \text { accidents } /(\text { year }-\mathrm{km}) .
$$




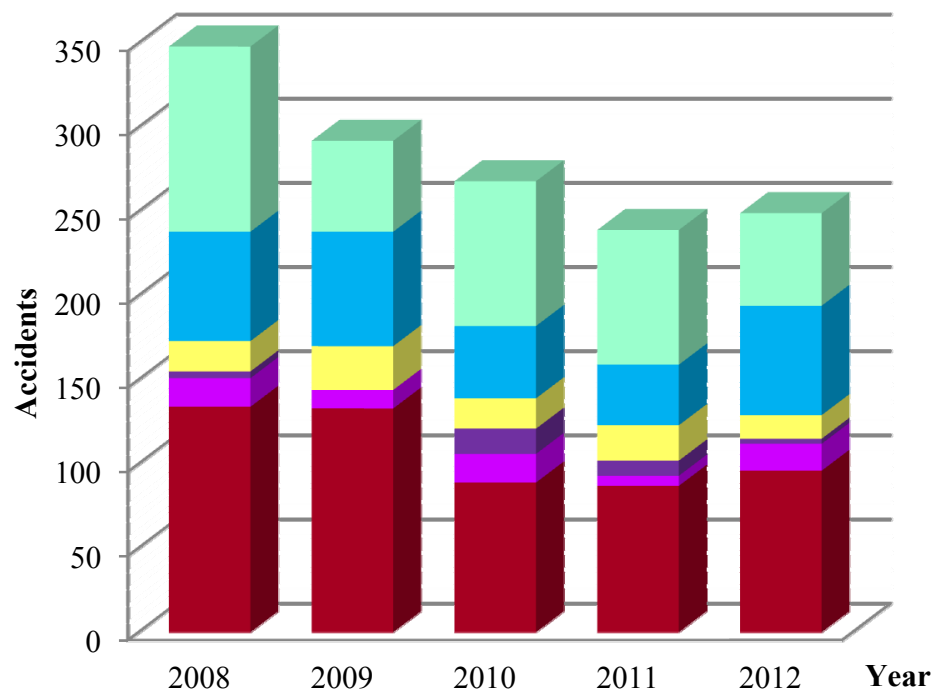

Legend

- disobeying vehicle giving way regulations

- disobeying traffic signal

- disobeying limit distances between vehicles speed misadjust for traffic condition

- disobeying priority regulations for pedestrians

pedestrian improper crossing

Figure 6: Evolution of road accidents by causes in Bucharest in period 20082012.

We include in the analysis the values for ID 10 and 12 (Table 1) (cases with significant different values of $A$ for the same values of $\mathrm{x}_{1}$ and $\mathrm{x}_{2}$ ). The values of standard deviation are calculated for:

1. recorded data: $\bar{A} \cong 11.7$ and $\sigma_{A}=14.7$, respective,

2. estimated values by eqn. (4): $\bar{A} \cong 13.8$ and $\sigma_{A}=15.8$.

Considerable deviations (over 100\%) from the average value are observed in both situations of recorded and estimated values. The results obtained in this analysis demonstrate that the negative binomial distribution with over dispersion is the most appropriate method for accidents estimation. This conclusion is confirmed also by other studies [8,9]. Therefore we use this asumption for the further analysis for estimation of accidents. 


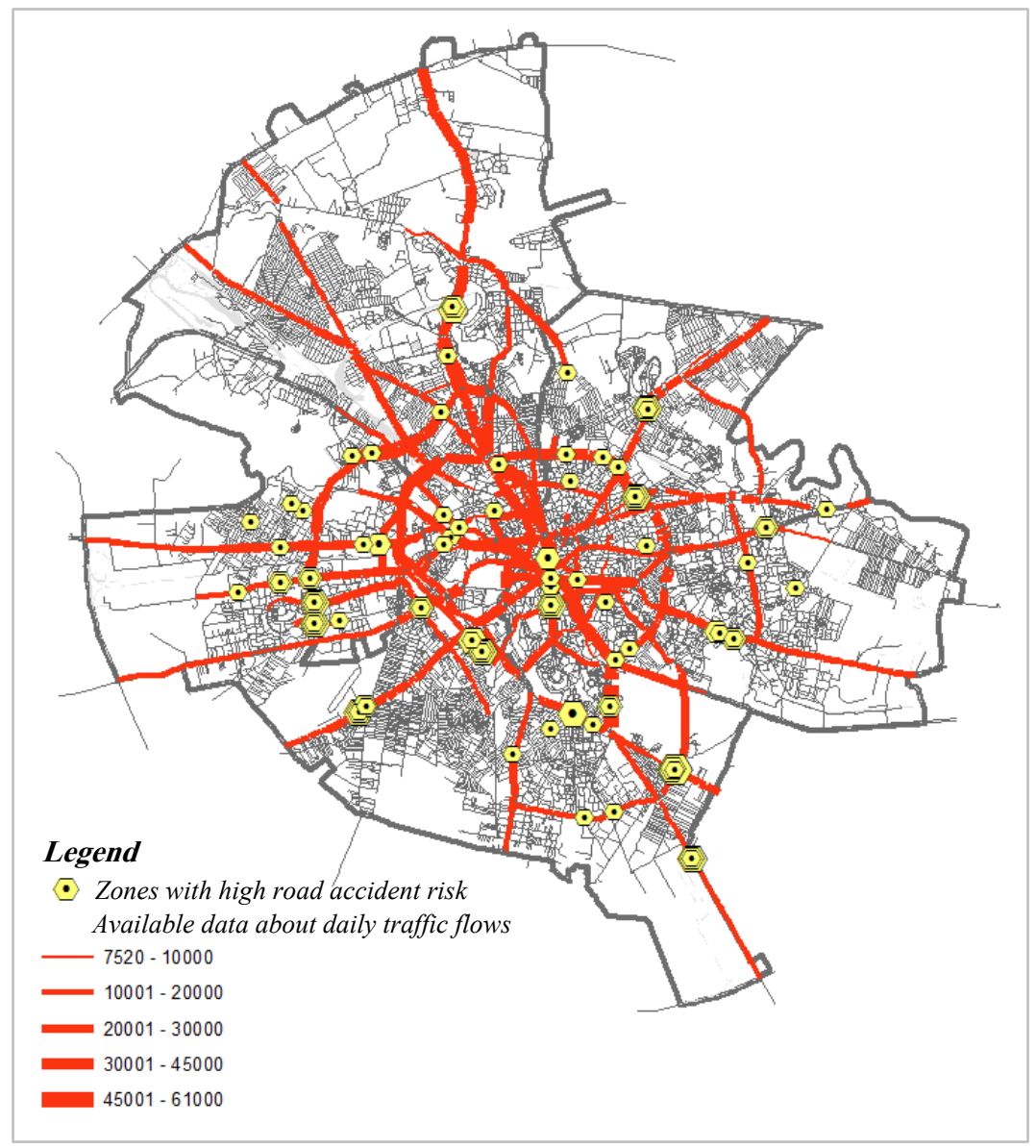

Figure 7: $\quad$ Location of zones with high risk of road accident.

The functionality of the model is validated for several selections of road sections from Bucharest areas where accidents were recorded. For that purpose we use the empirical Bayes method [10] in a short variant due to the reduced amount of available data.

We estimate the number of the future accidents for a road section unit by the equation:

$$
\hat{A}=\omega \cdot A-(1-\omega) \cdot A_{r}
$$

where $\hat{A}$ represents the estimated future accidents; $A$ - estimated accidents by eqn. (4) for specific attributes of the road section; $A_{y}$ - recorded accident on the road section in the previous period; $\omega$ - weight function $(0 \leq \omega \leq 1)$. 
Table 1: Example of selection of road section used for SFP calibration.

\begin{tabular}{|c|l|c|c|c|c|c|c|}
\hline ID & Street name & $\begin{array}{c}\text { Section } \\
\text { code }\end{array}$ & $\begin{array}{c}\text { Length } \\
(\mathbf{m})\end{array}$ & $\begin{array}{c}\text { Accidents/ } \\
\mathbf{p e r i o d}\end{array}$ & $\begin{array}{c}\text { Accidents/ } \\
\mathbf{k m}\end{array}$ & $\mathbf{x}_{\mathbf{1}}$ & $\begin{array}{c}\mathbf{x} \\
\mathbf{2}\end{array}$ \\
\hline 1 & Sos. Virtutii & 143110111 & 582.5 & 4 & 7 & 4 & 0 \\
\hline 2 & $\begin{array}{l}\text { Calea } \\
\text { Vacaresti }\end{array}$ & 163131111 & 143.6 & 3 & 28 & 6 & 1 \\
\hline 3 & $\begin{array}{l}\text { B-dul. } \text { Iuliu } \\
\text { Maniu }\end{array}$ & 163202111 & 392.1 & 5 & 10 & 6 & 2 \\
\hline 4 & $\begin{array}{l}\text { B-dul. } \text { Iuliu } \\
\text { Maniu }\end{array}$ & 163200121 & 1548.6 & 4 & 2 & 6 & 0 \\
\hline 5 & $\begin{array}{l}\text { Splaiul } \\
\text { Independentei }\end{array}$ & 143302131 & 1133.8 & 5 & 3 & 4 & 2 \\
\hline 6 & $\begin{array}{l}\text { Splaiul } \\
\text { Independentei }\end{array}$ & 143302131 & 1133.8 & 3 & 3 & 4 & 2 \\
\hline 7 & \begin{tabular}{l} 
B-dul. Beijing \\
\hline 8
\end{tabular} & 263300121 & 555.8 & 3 & 9 & 6 & 0 \\
\hline 9 & $\begin{array}{l}\text { Bd. } \text { Beijing } \\
\text { Calea Serban } \\
\text { Voda }\end{array}$ & 233300021 & 232.4 & 4 & 17 & 3 & 0 \\
\hline 10 & $\begin{array}{l}\text { Sos. Stefan cel } \\
\text { Mare }\end{array}$ & 163332111 & 399.7 & 3 & 13 & 6 & 1 \\
\hline 11 & $\begin{array}{l}\text { Sos. Mihai } \\
\text { Bravu }\end{array}$ & 183332111 & 367.9 & 3 & 11 & 8 & 2 \\
\hline 12 & $\begin{array}{l}\text { B-dul. } \text { Camil } \\
\text { Ressu }\end{array}$ & 163312111 & 262.3 & 4 & 11 & 6 & 2 \\
\hline 13 & Sos. Berceni & 123300131 & 3260.6 & 5 & 2 & 2 & 0 \\
\hline
\end{tabular}

As we mentioned before, we assume that estimated accidents $A$ correspond to negative binomial distribution with the over dispersion $\rho$. For a road section the over dispersion $\rho$ is estimated per unit length. The weight function is determined by the equation:

$$
\omega=\frac{1}{1+\frac{A \cdot T}{\rho}},
$$

where $T$ is the period (in years) with available data on accidents.

The functionality of the model was demonstrated with eqns. (6) and (7) for a set of road sections.

The next step in modelling consists in SPF definition for intersections, which is a complex issue. By analysing the macroscopic urban network model a wide range of intersection configurations resulted. Each class of intersection needs appropriate SPF variables and parameters. An additional difficulty of parameter calibration is given by the characteristics of ground public transport infrastructure (with dedicated tram track or with tram track included in road infrastructure). Consequently, supplementary studies for SPF definition are necessary. 


\section{Conclusion}

Generally, even if the social accidents costs are evaluated being very high, the road safety impact has been seldom included in the urban traffic projects in the last two decades. Most of the urban transport and traffic studies have been focused on travel time, congestion, environmental impact, without taking into account the safety estimation. Recently the transport and traffic specialists concluded that road safety has to represent an additional criterion in selection of the best planning alternatives. The settled goal is the a-priori minimization of road accidents number for each studied alternative. Throughout the presented model we intend to develop geodatabases structures, methods and models for estimating the safety performance and number of accidents at the planning and designing step. Simulation tools will be developed in order to analyse different scenarios and traffic flows patterns and to identify appropriate solutions for safety performance improvement.

In order to achieve this goal further research on several complexes modelling issues are required:

- Definition of safety performance functions appropriate for inhomogeneous and complex intersections of Bucharest road network. In literature there is no definition of safety performance functions which include transit flow vehicles. Because in Bucharest road network and ground transit network are located in the same urban area, multiple connexions exist between the two networks; these connexions have to be modelled in studies on urban road safety

- Calibrating of safety performance function parameters taking into account the fluctuant Bucharest traffic flow pattern and the impact of trams and light-train transit services on road safety performances.

\section{Acknowledgements}

This paper includes research from the project "Research on estimation and enhancement of intrinsic safety performances for urban traffic networks SAFENET', contract 193/2012, funding by Program Partnerships - PN II supported by ANCS, CNDI - UEFISCDI (Executive Agency for Higher Education, Research, Development and Innovation Funding).

\section{References}

[1] CARE, EU road accidents database; European Commission - Directorate General for Mobility and Transport, 2013, http://ec.europa.eu/transport/ road_safety/specialist/statistics/.

[2] Qin X., Ivan J.N., Ravishanker N. \& Liu J., Hierarchical Bayesian Estimation of Safety Performance Functions for Two-Lane Highways Using Markov Chain Monte Carlo Modelling, Journal of Transportation Engineering, Vol. 131 No. 5, pp. 345-351, 2005. 
[3] Lord, D. \& Bonneson, J.A., Role and Application of Accident Modification Factors within the Highway Design Process. Transportation Research Record: Journal of the Transportation Research Board, Vol. 1961, pp. 65-73, 2006.

[4] Harwood D.W., Council F.M., Hauer E., Hughes W.E. \& Vogt A., Prediction of expected safety performance on rural two-lane highways", Report No. FHWA-RD-99-207, US Department of Transportation, Federal Highway Administration, 2000.

[5] Elvik, R., Developing accident modification functions: exploratory study. Transportation Research Record: Journal of the Transportation Research Board, Vol. 2103, pp. 18-24, 2009.

[6] Lord, D. \& Persaud B.N., Estimating the safety performance of urban road transportation networks. Accident Analysis \& Prevention, Vol. 36, Issue 4, pp. 609-620, 2004.

[7] Gaudry, M. \& Lassarre, S., (eds). Structural Road Accident Models: The International Drag Family, Elsevier Science, Pergamon Press, 2000.

[8] Hauer, E., Observational Before-After Studies in Road Safety, Elsevier Science Ltd., Pergamon Press, 1997.

[9] Gaudry, M. \& Gefrin Y., Economie de la sécurité routière : enjeux, état des lieux et réflexions prospectives, La documentation française: Paris; 2007.

[10] Hauer, E., Harwood, D. W., Council, F. M. \& Griffith M. S., Estimating Safety by the Empirical Method: A Tutorial. Transportation Research Record: Journal of the Transportation Research Board, No. 1784, Washington, D.C., pp. 126-131, 2002. 